\title{
RESEARCH OF VITIS VINIFERA LEAVES EXTRACTION PROCESS ON TIMATIC LABORATORY EXTRACTOR
}

\author{
Dmytro Soldatov, Sergey Stepanenko, Iryna Sayko, Halyna Kukhtenko \\ Industrial Pharmacy Department, National University of Pharmacy, Ukraine
}

\begin{abstract}
INTRODUCTION: Herbal medicinal products are widely used for prevention and treatment of many diseases.

AIM: The aim of our work was to study the parameters of grape leaves extraction on a laboratory extractor Timatic Micro.

MATERIALS AND METHODS: Towards achieving the goal, the tasks of determining the following factors influencing the grape leaves extraction were set: the degree of grinding and extraction time.

Timatic Micro extractor was used for extraction. This contemporary technology is based on a double action of pressure - reduction of the pressure and percolation of biological material that intensifies extraction process. The extractant used was $\mathbf{4 0 \%}$ ethyl alcohol as it provides maximum extraction of flavonoids and tannins. The extractor was set with standard parameters: compression - 2 minutes, decompression - 2 minutes.
\end{abstract}

RESULTS AND DISCUSSION: The degree of raw material depletion in the main biologically active substances of common grape leaves (tannins and flavonoids) significantly increases with decreasing the size of crushed grape leaves, and is the highest in the fraction less than $1 \mathrm{~mm}$ and is $69.93 \%, 44.13 \%$ and $78.48 \%$ for extractives, tannins, and flavonoids, respectively (extraction time - $2 \mathrm{~h}$ ). With increasing the time of extraction up to $4 \mathrm{~h}$ the yield of extractible substances increases by an average of $3 \%$, but for 2 hours quite intensive extraction occurs, which gives high rates of raw material depletion.

For obtaining the extract in the laboratory extractor Timatic, we have chosen as raw material a fraction of grape leaves of less than $1 \mathrm{~mm}$ and extraction time of 2 hours.

CONCLUSION: The presented method has proven its reliability and efficiency in the extraction of substances in question.

Keywords: Vitis vinifera, extraction, Timatic Micro; flavonoids, ethyl alcohol

Address for correspondence:

Sergey Stepanenko

National University of Pharmacy

53 Pushkins'ka St

Kharkiv

Ukraine

e-mail:step1enko@gmail.com

Received: April 5, 2019

Accepted: June 182019

\section{INTRODUCTION}

Currently in clinical practice an important place is occupied by herbal medicinal products, as they have a wide range of biological effects and low frequency of side effects. This makes them beneficial for prevention and treatment of many diseases. 
Plant-derived medicines are included in more than 85 pharmacological groups of drugs and most of them have no equivalent synthetic substitutes (1).

Mostly, herbal drugs are antitussives, expectorants, laxatives, astringents, and others. This is explained by the fact that numerous natural compounds, despite the high level of organic chemistry development, until now have been either impossible or economically inefficient to synthesize (1-7).

A significant share of herbal medicinal products in pharmaceutical industries are obtained by extraction, so it is important to find the optimal conditions for the extraction process in which the yield of biologically active substances is maximum, and their destruction under the influence of temperature and solvent is minimal (8-12).

The source of raw materialsa in the production of drugs in Ukraine are wild medicinal plants, plants that are cultivated and imported raw materials.

Quite little attention in the pharmaceutical industry is paid to such raw materials as leaves of $\mathrm{Vi}$ tis vinifera.

Common grape is grown almost throughout Ukraine, and mostly in the steppe and forest-steppe areas in Transcarpathia in the South.

Common grape vine (Vitis vinifera L.) is a woody vine of the family Vitaceae with stems up to $30 \mathrm{~m}$. The leaves are alternate, large, roundish in outline, kidney-shaped or pentagonal, entire or threeor five-lobed. In addition to the leaves on the shoots, there are tendrils that cling to support the plant. Inflorescences are composed of small flowers. The fruits - berries, are very different with different varieties in shape, size, color, and taste (13).

Grape is a promising source of biologically active substances. In the industry grape fruits are used to produce wines and the seeds - for obtaining oil.

Flavonoids of common grape leaves determine its P-vitamin, antispasmodic, antioxidant, choleretic action that allows using it to treat diseases of blood vessels (increasing their resistance, increasing flexibility and throughput), the hepatobiliary system, and the gastrointestinal tract. Polyphenols complement and potentiate the mutual action of flavonoids in capillaries (14).
All natural flavonoids are low-toxic, with a wide spectrum of biological action, which makes them attractive for new phytomedicines creation.

Considering the trend of an increase in liver, respiratory, and cardiovascular diseases, and the fairly wide spread and availability of raw materials, the content of a large number of biologically active substances in the leaves of common grape, the study of extraction process and obtaining the extract for further production of drugs on its basis are relevant.

The main stage of phytopreparation production is extraction of plant material caused by the general laws of mass transfer, the properties of plant cells and the physico-chemical affinity of the extractant and substances that are extracted. Extraction is a complex process that involves dialysis, desorption, diffusion and dissolution occurring randomly and simultaneously as a common process (8).

Raw materials for the majority of the drugs are dried parts of plants.

The process of extracting the dried material can be divided into several stages: penetration of extractant inside the plant material particles; wetting of substances that are inside the cell; the process of dissolution of biologically active substances that are on the cell walls in the form of pieces of dry material (formation of "primary juice"); and mass transfer of substances from the surface of the plant material to the solution.

Factors affecting the efficiency of extraction are as follows: hydrodynamic conditions, the surface of phase separation, concentration difference, the duration of the process, the viscosity of the extractant, and temperature. In addition, completeness and speed of extraction depend on the addition of surfactants, the nature of material loading, the choice of extractant, porosity and fractional void volume of raw material, leaching rate, the effect of vibration, pulsation, electric discharge in liquid medium, crushing and deformation of materials in the extractant.

Classical methods of extraction (maceration in various combinations) are based on the equilibrium of the substances extracted, in the total mass of extractant in the slow internal diffusion through cell membranes. Extraction processes are continued with the period of time ranging from 24 to 200 hours. The 
Dmytro Soldatov, Sergey Stepanenko, Iryna Sayko et al.

degree of plant material depletion hardly reaches $60 \%(8)$.

Percolation methods are based on extractant filtration through a layer of particulate material. It involves raw wetting, dissolving and washing away substances from the surface of the particles, the displacement of concentrated extracts.

Over the past decade, various ways to intensify the extraction process have been proposed. However, despite the significant progress in this area, there still are several problems to be solved. Most methods, such as vortex extraction, extraction using rotary pulsating apparatus, allow a significant acceleration of the process of mass transfer. However, due to milling of raw material and leaching of macromolecular compounds of damaged cells, the extracts produced are turbid, with a high content of fine solids.

The disadvantages of ultrasonic treatment include adverse impact on staff. In addition, ultrasonic vibrations cause cavitation, ionization of molecules, change of biologically active substance properties, reduction or increase of their therapeutic activity.

Timatic Micro extractor is a modern, economic and efficient system for extracting components from biological materials.

Extraction is conducted at room temperature and the resulting extract retains the same natural properties and characteristics of active ingredients. The level of medicinal plant depletion is much higher than in traditional extraction methods, such as maceration, percolation and infusion. This contemporary technology allows for different types of solvents (water, alcohols, glycerol, oils) and is based on the double action of pressure - reduced pressure and percolation through biological material $(15,16)$.

The extraction cycle includes alternation of a dynamic phase and a programmable pressure maintenance phase, during which the extract is absorbed by the solvent. At the end of the cycle, using automatic pressure control, excess pressure is created in the chamber to maximize extraction. The double action of pistons, bursting solvent in the material, provides fluid motion in the extraction chamber and prevents the oversaturation of the product. Cycles can automatically be repeated a specified number of times, and this repetition ensures complete and qualitative extraction of active ingredients, especially when working with hard material, such as roots, bark and leaves.

Extractors of the Timatic company are operated by programmed parameters of pressure and temperature. This simplifies the work in obtaining extracts from materials such as flowers, fruits, bark, roots, buds, and stems, and medical, spicy and aromatic plants (Timatic Micro).

The most reasonable equipment for obtaining extract from grape leaves is Timatic Micro extractor

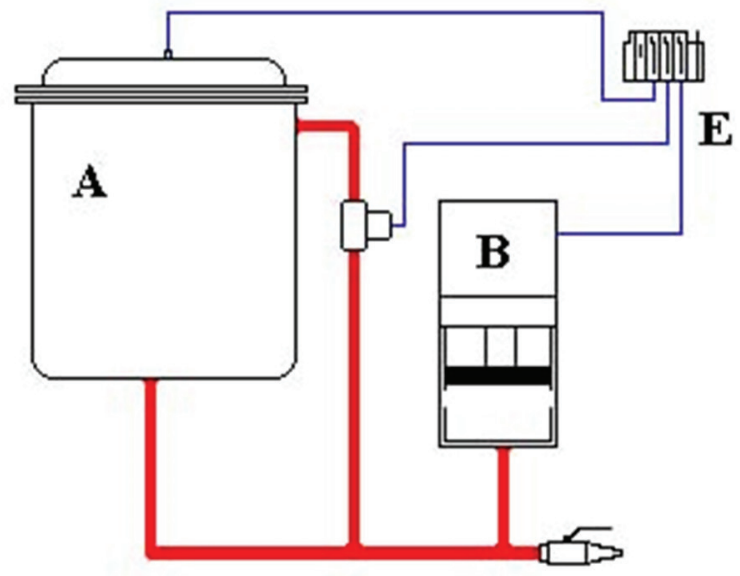

Fig. 1. Scheme of Timatic Micro operation

$A$ - extraction chamber; $B$ - Active rod;

E- pneumatic valve.

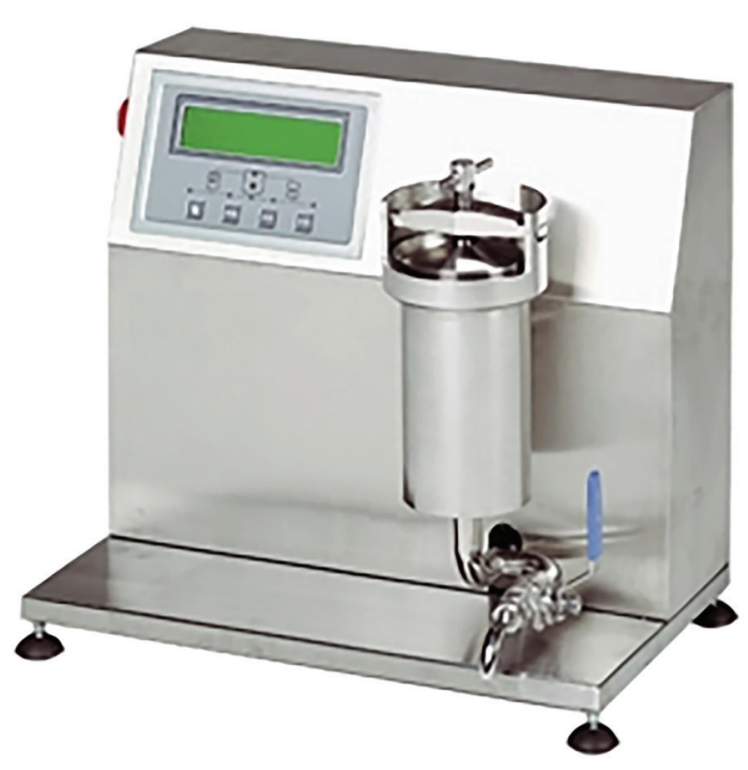

Fig. 2. Extractor Timatic Micro 
for which it is necessary to determine the influence of a certain number of factors that directly affect the extraction process.

In this context, the aim of our work was to study parameters of grape leaves extraction on a laboratory extractor Timatic Micro. Towards achieving the goal, the tasks of determining the following factors' influence on the grape leaves extraction have been set:

1. The degree of grinding;

2. The time of extraction.

\section{MATERIALS AND METHODS}

\section{Materials}

The objects of study are grape leaves, ethanol $40 \%$, purified water.

Vitis vinifera leaves. Large green leaves, grayish-green, rounded in outline. The surface is uniformly wrinkled, with a dense network of veins, smooth. The smell is fragrant. In the leaves contain tannins, organic acids, flavonoids, hydroxycoumarins, and derivatives of cinnamic acid.

Ethanol 40\%. A colorless, clear, volatile, flammable, hygroscopic liquid with a characteristic odor and burning taste. Miscible in all proportions with water, ether, chloroform, acetone and glycerol.

Purified water. A clear, colorless liquid, intended for the manufacture of drugs. Obtained from potable water. It must withstand the test of chlorides, sulfates, nitrates and nitrites, restoring substances, ammonia, calcium, heavy metals. The content of microorganisms is also standardized. It must meet the requirements for drinking water (less than $100 \mathrm{mi}-$ croorganisms in $1 \mathrm{~mL}$ ) in the absence of Enterobacteriaceae family bacteria, Staphylococcus aureus, Pseudomonas aeruginosa.

\section{Methods}

\subsection{Determination of Moisture Content}

Determination of moisture content was performed in express moisture analyzer Sartorius MA-150.

About 5 grams of minced raw material were placed in a cup of express moisture analyzer. Recorded sample weight before drying. The sample was dried using infrared ceramic heater at $105^{\circ} \mathrm{C}$. Drying continued to constant weight. Moisture content was determined by the device automatically using the difference in weight before and after drying to constant weight.

$$
X=\frac{m_{0}-m}{m_{0}}
$$

where

$\mathrm{m}_{0}$ - weight of the sample before drying, g;

$\mathrm{m}$ - weight of the sample after drying to constant weight, $g$

\subsection{Determination of Extractive Content}

Determination of extractives was performed by the method described below. Purified water and ethyl alcohol $40 \%$ were used as extractants.

Determination of extractives in raw materials was carried out in the absence of normative and technical documentation for the method of active ingredient quantification.

About $1 \mathrm{~g}$ of minced raw (accurate sample) was sifted through a sieve with apertures $1 \mathrm{~mm}$ in diameter and placed in a conical flask with a capacity of $200-250 \mathrm{~mL}, 50 \mathrm{~mL}$ of solvent specified in the relevant reference documentation for medicinal herbs were added, the flask was closed with stopper, weighed (with an accuracy of $\pm 0.01 \mathrm{~g}$ ) and left for 1 hour. Then the flask was connected to a reflux condenser and heated maintaining a weak boil for 2 hours. After cooling, the flask with the content was closed with the same stopper again, weighed and the loss in weight was refilled with the solvent. The content of the flask was thoroughly shaken and filtered through a dry filter paper to a dry conical flask of $150-200 \mathrm{~mL}$. A total of $25 \mathrm{ml}$ of filtrate was transferred with pipette to a pre-dried at a temperature of 100-105 degrees to constant weight and weighed accurately porcelain cup with a diameter of 7-9 $\mathrm{cm}$ and evaporated to dryness in a water bath. The cup with the residue was dried at a temperature of 100-105 degrees to constant weight, then cooled for 30 minutes in desiccator, the bottom of which is anhydrous calcium chloride, and instantly weighed.

The content of extractives as percentage $(\mathrm{X})$ in terms of absolute dry raw material is calculated as follows: 


$$
\mathrm{X}=\frac{\mathrm{m} \cdot 200 \cdot 100}{\mathrm{~m}_{1} \cdot(100-\mathrm{W})}
$$

where

$\mathrm{m}$ - weight of dry residue, g;

$\mathrm{m}_{1}$ - weight of raw materials, $\mathrm{g}$;

$\mathrm{W}$ - loss in weight in the drying of raw materials, \%.

\subsection{Quantification of Tannins}

About $2 \mathrm{~g}$ (accurate sample) of chopped raw material was sifted through a sieve with aperture diameter of $1 \mathrm{~mm}$, placed in a conical flask of $500 \mathrm{~mL}$, $250 \mathrm{~mL}$ of hot boiling water was poured and refluxed in an electric furnace with a closed spiral for $30 \mathrm{~min}$ utes, stirring occasionally. The liquid was cooled to room temperature and about $100 \mathrm{~mL}$ were filtered to Erlenmeyer flask of $200-250 \mathrm{~mL}$ through cotton so that the material particles did not get into the flask. Then $25 \mathrm{~mL}$ of the obtained extract were transferred with a pipette to another Erlenmeyer flask of $750 \mathrm{~mL}$, $500 \mathrm{~mL}$ of water were added, then $25 \mathrm{~mL}$ of indigo sulfonic acid and titrated at constant stirring with solution of potassium permanganate $(0.02 \mathrm{~mol} / \mathrm{L})$ to golden-yellow colouring.

In parallel, a control experiment was conducted.

One $\mathrm{mL}$ of potassium permanganate $(0.02$ $\mathrm{mol} / \mathrm{L}$ ) corresponds to 0.004157 grams of tannins in terms of tannin.

The content of tannins in terms of absolute dry raw as percentage $(\mathrm{X})$ was calculated using the formula:

$$
X=\frac{\left(V-V_{1}\right) \cdot 0.004157 \cdot 250 \cdot 100 \cdot 100}{m \cdot 25 \cdot(100-W)}
$$

where

$\mathrm{V}$ - volume of potassium permanganate solution $(0.02 \mathrm{~mol} / \mathrm{L})$ spent on drawing titration, $\mathrm{ml}$;

$\mathrm{V}_{1}$ - volume of potassium permanganate solution $(0.02 \mathrm{~mol} / \mathrm{L})$ spent on titration in the control experiment, $\mathrm{mL}$;

0.004157 - amount of tannins, which corresponds to $1 \mathrm{~mL}$ of potassium permanganate $(0.02$ $\mathrm{mol} / \mathrm{L}$ ) (in terms of tannin), g;

$\mathrm{m}$ - weight of raw material, $\mathrm{g}$;

$\mathrm{W}$ - loss in weight when drying, \%;
250 - total volume of extraction, $\mathrm{mL}$;

25 - volume of extract taken for titration, $\mathrm{mL}$.

\section{Material}

\subsection{Quantification of Flavonoids in Raw}

Approximately $1.0 \mathrm{~g}$ (accurate sample) of raw material was crushed to the size of particles passing through a sieve with holes $2 \mathrm{~mm}$ in diameter, then placed in a ground joint flask with a capacity of $150 \mathrm{~mL}$, and $30 \mathrm{~mL}$ of $50 \%$ alcohol were added. The flask was attached to a reflux and heated in a water bath for 30 minutes, shaking occasionally for flushing raw material particles from the walls. Hot extractions were filtered through cotton wool in a volumetric flask of $100 \mathrm{~mL}$, so that the particles of raw materials were not exposed to the filter. The cotton was transferred to a flask for extraction and $30 \mathrm{~mL}$ of $50 \%$ alcohol were added. Extraction was repeated twice more in the above conditions, filtering extractions in the same volumetric flask. After cooling, the volumes of extracts were adjusted to mark with 50\% alcohol and stirred (solution A).

In the $25 \mathrm{~mL}$ volumetric flask $1 \mathrm{~mL}$ of solution A was transferred, as well as 1 drop of diluted acetic acid, $1 \mathrm{~mL}$ of aluminum chloride solution in 95\% alcohol solution, and the volume was adjusted with 95\% alcohol to the mark. After 40 minutes, the optical density of the solution was measured in a spectrophotometer at a wavelength of $415 \mathrm{~nm}$ in a cell with layer thickness of $10 \mathrm{~mm}$. A solution consisting of 1 $\mathrm{ml}$ of extract and 1 drop of diluted acetic acid was used as reference solution. It was brought to the mark by $95 \%$ alcohol in a $25 \mathrm{ml}$ volumetric flask.

In parallel the optical density of a standard reference sample (SRS) of rutin was measured. It was prepared as follows. In the $25 \mathrm{~mL}$ volumetric flask $0.5 \mathrm{~mL}$ SRS of rutin were transferred, as well as 1 drop of diluted acetic acid, $1 \mathrm{~mL}$ of aluminum chloride in $95 \%$ alcohol solution and the volume was adjusted with 95\% alcohol to the mark.

The content of the sum of flavonoids in terms of rutin and absolute dry raw material was calculated as percentage $(\mathrm{X})$ using the formula:

$$
\mathrm{X}=\frac{\mathrm{A} \cdot \mathrm{m}_{0} \cdot 100 \cdot 0,5 \cdot 25 \cdot 100 \cdot 100 \cdot \mathrm{B}}{\mathrm{A}_{0} \cdot \mathrm{m} \cdot 100 \cdot 1 \cdot 25 \cdot(100-\mathrm{W}) \cdot 100}
$$

where 
A - optical absorbtion of the test solution;

$\mathrm{A}_{0}$ - optical absorbtion of rutin SSS;

$\mathrm{M}$ - weight of raw material, g;

$\mathrm{m}_{0}$ - weight of rutin SRS, g;

$\mathrm{B}$ - content of rutin in SRS, \%;

$\mathrm{W}$ - the loss in weight at drying, \%.

\subsection{Extraction Technology}

The technology of dry extract obtaining comprises the following steps: extraction of raw materials, purification of extraction, evaporation of the alcohol extraction, and drying of the condensed extraction.

Timatic Micro is used for extraction. This extractor operates at ambient temperature, thus preserving the natural properties and characteristics of the active components of the leaves of common grapes. This modern technology is based on a dual action of pressure - reduced pressure and percolation of the plant material. The extractant used was $40 \%$ ethyl alcohol for maximum extraction of flavonoids and tannins.

Empirically it has been found that the optimum ratio of raw material:extractant is 1:15.

Thus, the weight of raw material was $60.0 \mathrm{~g}$, and the volume of $40 \%$ ethanol - $900 \mathrm{~mL}$.

In order to justify the degree of initial raw material shredding, comparative research on the depletion of raw materials in terms of extractives, tannins and flavonoids has been conducted.

For this purpose, in laboratory grinder grape leaves were crushed and sieved through sieves of appropriate hole size. Three fractions were: from 1 to $2 \mathrm{~mm}, 2$ to $3 \mathrm{~mm}$, and less than $1 \mathrm{~mm}$. The extraction of samples was conducted in laboratory extractor Timatic Micro. First, prepared raw material was weighed on laboratory scales (60.0 g of crushed grape leaves); extractant - in a graduated cylinder $900 \mathrm{~mL}$ of $40 \%$ ethyl alcohol were obtained from $96 \%$ ethyl alcohol and distilled water. Later, $60.0 \mathrm{~g}$ of crushed grape leaves were loaded in the filter bag, it was closed with a clip and put into the extractor's extractive chamber and filled with $900 \mathrm{~mL}$ of $40 \%$ ethanol. The extractor was programmed with standard parameters: compression - 2 minutes, decompression - 2 minutes, time of extraction - 120 minutes, number of extraction cycles - 30 .

\section{RESULTS AND DISCUSSION}

Purified water and $40 \%$ ethyl alcohol were used as extractants. The content of extractives in grape leaves using water and $40 \%$ ethanol as extractants was $35.86 \pm 0.24 \%$ and $20.85 \pm 0.56 \%$ respectively. According to the literature, the most optimal extractant for major biologically active substances of common grape leaves (tannins and flavonoids) is $40 \%$ ethyl alcohol. Using purified water as extractant obtained a higher yield of extractives, as compared to $40 \%$ ethanol, due to greater solubility of related substances of grape leaves in water.

After the extraction content and exhaustion degree of extractives, tannins and flavonoids have been determined (Fig. 3, Fig. 4).

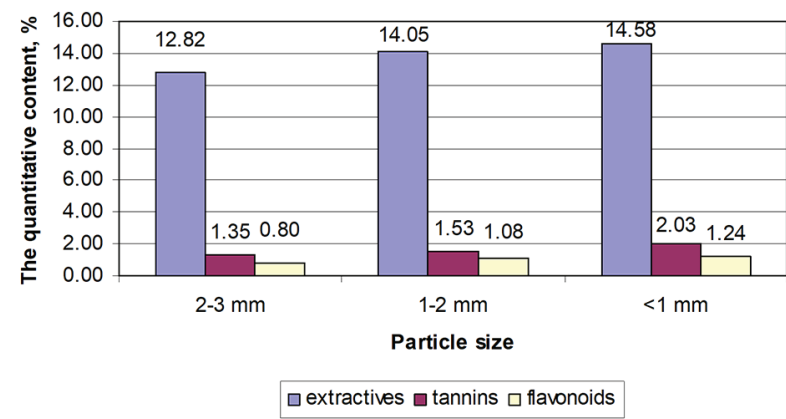

Fig. 3. The quantitative content of extractives, tannins and flavonoids in extracts of various fractions at standard extraction parameters

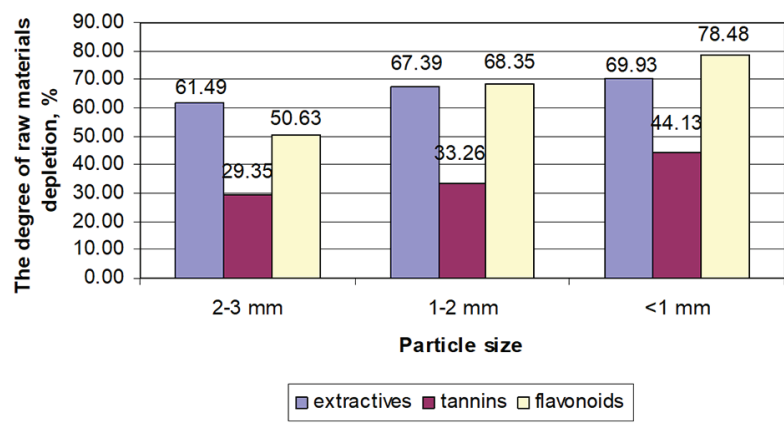

Fig. 4. The degree of raw material depletion in terms of extractives, tannins and flavonoids in extracts of various fractions at standard extraction parameters

In order to justify the extraction time, extraction was performed for 2 and 4 hours. The resulting extract was tested for the presence of extractives, tannins and flavonoids (Fig. 5, 6). 
Dmytro Soldatov, Sergey Stepanenko, Iryna Sayko et al.

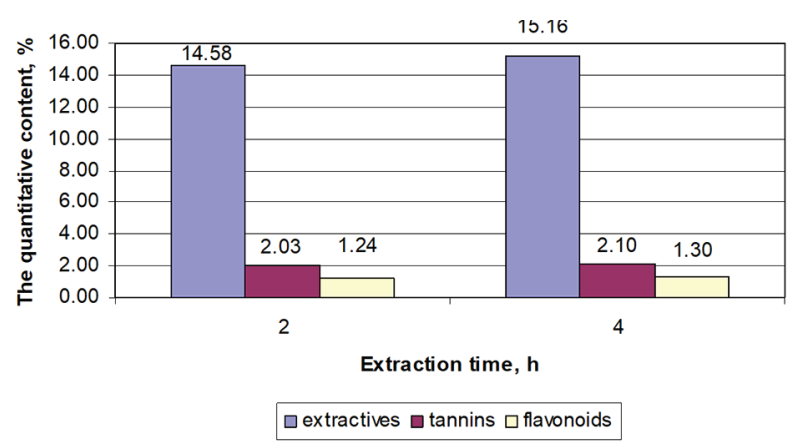

Fig. 5. The quantitative content of extractives, tannins and flavonoids in extracts at different times of extraction

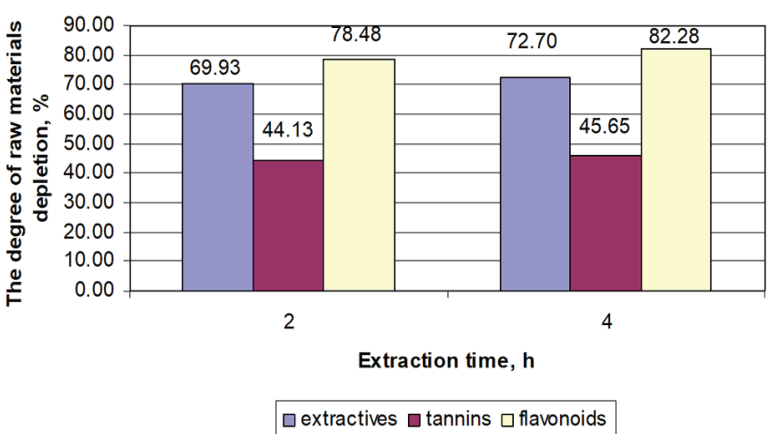

Fig. 6. The degree of raw material depletion in extractives, tannins and flavonoids in extracts at different times of extraction

As it can be seen on the diagram (Fig. 4), the degree of raw material depletion in the main biologically active substances of common grape leaves (tannins and flavonoids) significantly increases with the decrease of the size of crushed grape leaves, and is the highest in the fraction less than $1 \mathrm{~mm}$ and is $69.93 \%$, $44.13 \%$ and $78.48 \%$ for extractives, tannins, and flavonoids, respectively.

With the increase of the time of extraction, the yield of extractible substances increases by an average of 3\%, but for 2 hours quite intensive extraction occurs, which gives high rates of raw material depletion.

Therefore, for obtaining the extract in the laboratory extractor Timatic we have chosen as raw material fraction of grape leaves less than $1 \mathrm{~mm}$ and extraction time 2 hours.

\section{CONCLUSION}

The present article describes extraction by a modern, efficient system for extracting components from biological materials. Grape leaves have been ex- tracted using Timatic Micro laboratory extractor. In a series of experiments, extractibles, tannins and flavonoids have been extracted by $40 \%$ ethanol solution. The presented method has proven its reliability and efficiency in the extraction of substances in question.

It has been experimentally proven, that with the decrease in raw material particle size, the yield of extractibles, tannins and flavonoids increases. With particle size under $1 \mathrm{~mm}$, the yield of extractibles reaches $69.93 \%$, tannins - 44.13\%, flavonoids $78.48 \%$. A further decrease in particle size is not expedient as it leads to pollution of the extract with the finest particles. In industial production, the purification of such extracts might be complicated.

The increase in extraction duration (over 2 hours) does not lead to any significant increase in the yield of extractibles, tannins and flavonoids.

Thus, it has been experimentally proven that the optimal parameters of common grape leaves extraction by $40 \%$ ethyl alcohol on Timatic Micro extractor are as follows: degree of plant material crushing - less than $1 \mathrm{~mm}$; temperature - ambient; raw:extractant ratio of 1:15; extraction time - 2 hours.

\section{REFERENCES}

1. Reference documents of Ukrainian Ministry of healthcare. Available from: http://mozdocs.kiev.ua/

2. Omirbaeyeva AE. Study of Carduus crispus dense extracts anti-inflamatory activity. Asian J Sci Educ Res. 2015; 1(17):1004-9.

3. Alimova US. The study of the antimicrobial activity of $\mathrm{CO} 2$ extracts of Plantago major and Acopus calamus. World J Pharm Sci. 2015; 3(5):826-9.

4. Omirbaeyeva AE. The study of biological active substances of thistle curled (Carduus crispus L.). Int J Pharmacogn Phytochem Res. 2016;8(2):297-9.

5. Gladukh YeV, Seguy AM. The study of pharmacotechnological parameters of burdock (Arctium lappa) leaves. J Chem Pharm Res. 2016;8(1):260-4.

6. Gulmurodov IS, Gladukh YeV. The study of rheological properties of the fatty ointment base for topical treatment of colds. J Chem Pharm Res. 2015;7(10):788-96.

7. Makhsudov K, Stepanenko SV, Gladukh YeV. Pharmaceutical development of ointment for the first phase of wound healing with chamomile extract content. Be in progress 2: International confer- 
ence of pharmacy students, Lublin, 21st-25th April, 2016. Lublin, 2016. p. 13.

8. Yudina YuV, Shmyrova YuV, Stepanenko SV, Gladukh IeV, Chyieshov VI, Sichkar AA, et al. Industrial drug technology: tutorial for laboratory classes for students of speciality "Pharmacy". Kharkiv: Original; 2012.

9. Kumarova AK, Gladukh YeV, Kukhtenko GP. Research of the extraction process in the preparation of camel thorn dense extract. Topical issues of new drugs development: abstracts of international scientific and practical conference of young scientists and student, April 23, 2015. Kharkiv; 2015. p. 205-206.

10. Rakhmonov AU, Kukhtenko GP, Gladukh YeV. Research of the liquid nettle leaves extract obtaining by percolation method. Topical issues of new drugs development: abstracts of international scientific and practical conference of young scientists and student, April 23, 2015. Kharkiv; 2015. p. 165.

11. Kha DA, Kukhtenko OS, Gladukh YeV. Development of technology for producing compound thick extract obtained by common extraction of thyme, yarrow, chamomile and eucalyptus. Topical issues of new drugs development: abstracts of XXIII international scientific and practical conference of young scientists and student, April 21, 2016. Kharkiv; 2016 (1). p. 267.
12. Iudina Yu. The study of the calendula flowers extraction process. Visnyk pharmacii. 2015; 3(83):28-31.

13. Vinograd kulturnij. Available from: http:// www.pharmencyclopedia.com.ua/article/1711/ vinograd-kulturnij

14. Dresch R, Dresch M, Guerreiro A, Biegelmeyer R, Holzschuh M, Rambo D, Henriques A. Phenolic compounds from the leaves of Vitis labrusca and Vitis vinifera L. as a source of waste byproducts: development and validation of LC method and antichemotactic activity. Food Anal Methods. 2014; 7:527-39.

15. Bondarenko AS, Bevz NY, Gladukh IeV, Soldatov DP. Quantification of the main active ingredients of plant extracts to establish optimal conditions for extraction. J Chem Pharm Res. 2015;7(2):618-25

16. Timatic Micro. Available from: http://www.timatic.it/index.php/en/products/extractors-of-active/ timatic-micro 